\title{
Method to Design and Analyze an Interactive Product Based on Design Elements for Creating an IoT-based Service
}

\author{
Hyeji Shin ${ }^{1}$, Bienil Jeon ${ }^{2}$ and Jae Wan Park ${ }^{3, *}$ \\ ${ }^{1}$ Global School of Media, Soongsil University \\ ${ }^{2,3}$ Dept. of Digital Media, Soongsil University \\ 120122690@ssu.ac.kr, ${ }^{2}$ jeonbien@ssu.ac.kr, ${ }^{3}$ jaewan.park@ssu.ac.kr
}

\begin{abstract}
Interactive products based on the Internet of Things play an important role in contemporary environments. With the advance of IoT technology, servitiation of products is emerging, and rapidly progressing. These interactive products need to be regarded from a service design approach, instead of a traditional des gn approach. However, methods with design elements that reflect the characteristies of IoT technologies have not yet been widely investigated. Thus, this research aims to build a method to design and analyze IoT-based interactive products based on new design elements. We commence by exploring the related literafure and cases in order to extract new design elements. Through these explorations, we construct considerable elements for effectively designing an IoT-based service. In order to prove the validity of the elements, we analyze cases of an IoT-based service rith the new destign elements. Through this, we build a method to design and analyze IoT-based interactive products based on four essential controllable factors of an DoT-based interactive system. This research contributes to a design method to enable designern to fully explore and better understand interactive products.
\end{abstract}

Keywords: Interactive Design, Internet of Things, Connected Product, Design Elements

\section{Introduction}

Interactive products cane defined as everyday objects that interact with a user's actions, and are embedded with computational power, such as input, process, and output devices [1]. Today these interactive products create value by adding services; i.e., servitization of a product is widely recognized as a way to create new value "by adding services to products" [2]. The advance of the Internet of Things (IoT) technology that through network connectivity allows everyday objects to collect and exchange data is rapidly progressing the servitization of products. Servitization enables smart, connected products to be considered as service components within a service design process. Thus, interactive products connected to a mobile application, a social network service, or an IoT platform need to be thought of in terms of service design, rather than traditional design.

Generally, service design functions as "a way to inform changes to an existing service, or create an entirely new service" [3]. The goal of the service design is to enhance interaction and its quality between the different stakeholders involved in a service. That is, service design can be considered as designing a touchpoint, which is interaction between a business and its customer, in order to satisfy the needs and objectives of both customers and service providers. IoT-based interactive products as service components can function to achieve a service goal that cannot be satisfied by traditional touchpoints, such as person-to-person communication, websites, or mobile applications. To design

* Corresponding Author 
these products, new design elements for attaining a service goal, in which the characteristics of an IoT service can be reflected, are needed in the design process of interactive products. However, methods for this have not been widely explored.

The purpose of this research is to build a method to design and analyze an interactive product based on new design elements that are extracted from IoT-based services. For this research, we first investigate literature related to IoT-based services, IoT platforms, and smart, connected products, and explore cases, in order to extract elements for designing and analyzing such smart, connected products. Based on these explorations, we build considerable elements for designing an IoT-based service. In order to prove the validity of the extracted design elements, we apply design elements to cases of an IoT-based service, and analyze them. Through this, we can confirm whether a service goal is achieved, and through which design elements. Based on the built design elements, we propose a method to design and analyze interactive products based on four essential controllable factors of an IoT-based interactive system in terms of a timescale, namely input, control, connectivity, and output. This research contributes to a design method by allowing designers to fully explore, better understand, and better design interactive products based on the service design process.

\section{Literature Review}

\subsection{IoT-based Service and Product Servitization}

Today, the IoT is considered as a global infrastructure that connects various physical objects and virtual environments [4]. The IoT can be defined as the network technology of physical objects that are embedded with sensors actuators, and communication technology [5,6]. The IoT enables these devices to collect environmental data, and interact with other things through communicating data. Recently, the IoT has focused on improving communication between people and environments on an Internet-based service. Today, IoT environments are moving toward the servitization of physical products. An IoT-based seryice can be divided into two parts: smart, connected products as service components andan IoT platform that bridges these smart, connected products. In service design, the target of service and its sensing scope need to be considered as a design element for creating a new service [7].

\subsection{Smart, Connected Products and Interactive Systems}

A smart, connected product is divided into three parts: 'physical component', 'smart component', and 'connectivity component' [8]. The physical components consist of mechanical and electronic parts. The smart component can enhance the capability of the physical component through interactive technology, including applications with a smart, connected product. Moreover, the connectivity component enables data to bi-directionally communicate among the products.

A smart, connected product can be considered as one kind of interactive system that allows significant amounts of interaction between users and the system. In designing a smart, connected product as a component of an IoT-based service, the degree of the user's conscious manipulation can be considered as an important design element in order to decide the scope of human intervention [7]. A smart, connected product can use various control systems, such as simple on/off and feedback loops, in order to provide optimal experience. Today, the smart, connected product is being developed as smarter interactive systems that move toward artificial intelligence [9]. The key element that is looping through an interactive system is information.

An interactive product as a system can be considered as the application of diverse control systems for looping an amount of information through minimal or reduced human 
intervention [10]. Users can achieve the goal of a service through optimized conscious manipulation.

\subsection{IoT Platform}

An IoT platform enables users to connect different smart objects or devices [11]. Based on the connection, an IoT platform can function to record, process, and visualize data. While users use a smart, connected product, the product is connected to an IoT Platform, and data collected by the product are sent to the IoT platform. Moreover, users and product providers can approach an IoT platform, and then operate each of its functions. Thus, the IoT platform plays a role in the infrastructure that enables users to communicate with various smart products or devices [12]. Because of these IoT platform features, smart, connected products can offer expandability. A smart, connected product can be indirectly connected to an IoT platform via smart devices, or can be directly connected to an IoT platform. The products connected to the IoT platform can seamlessly communicate data with other smart, connected products. Moreover, through physical objects in an IoT platform, information can be used to personalize a service. The physical objects can smartly interact with users, based on the user's patterns. Moreoyer, the physical objects can be customized for users through modularizing the physical objects. Today, a personalized IoT-based interactive product is being buil Within these considerations.

\section{Case Studies}

We explored cases of the latest smart connected product, in order to understand current trends of an IoT-based service and extract design elements. Today, smart, connected products are mainly being developed as everyday objects. Thus, the selected cases are concerned with the user's daily life. These cases are mostly composed of a connected product, and a mobile application or an IOT platform.

\subsection{GlowCap}

An objective of GlowCap is to facilitate medical care, by providing interaction between patients, doctors, and pharmacists The main function of GlowCap is to provide an alarm schedule for users to take the medioation. GlowCap is composed of a pill bottle, a cap device, and aplug-in reminder device [13]. The plug-in reminder and cap glow according to the user's schedule of talking medication, so that they can inform the user of the schedule. When the pill bottle is opened by users, the cap of the pill bottle senses the opening action of the puser. Also, the cap device and the reminder device are connected to the Internet, and the user's data of taking medicine are sent to the manufacturer [13]. However, if the users don't follow the schedule, the devices glow and make noises, and then send a text message or dial the user's home phone. Moreover, these data are sent to patients caregivers, and doctors to help their treatment. For requesting pills from a user's local pharmacy, the users can press a button in the base of the GlowCap. GlowCap provides feedback, in order to enhance interactions among different stakeholders in the service [14].

\subsection{HAPI Fork}

HAPI Fork aims to build a healthy eating habit by monitoring and tracking the user's daily eating habits. HAPI Fork helps the user maintain a healthy eating habit by informing users when their eating speed is excessive. This service is composed of a physical fork object, a mobile application, and an online dashboard. A 3-axis accelerometer within the fork device senses the user's "fork serving" from plate to mouth [15]. If intervals between these motions are less than $10 \mathrm{sec}$, it vibrates and glows with a red light. On the other hand, if the user maintains a moderate eating speed, it glows green light, and stops 
vibrating. The data collected by the fork is transferred to mobile applications through Bluetooth. Through USB, it can be connected with a computer, and then the data can be synchronized in the online dashboard. The Online dashboard functions are managing the data from the fork object, setting up the users' goal, and sharing mealtimes with friends. Also, according to the users' state, the online dashboard can show the differences between the users' present state and the goal. During the mealtime, users can check the results of times between fork servings and the whole mealtime in real time.

\subsection{Amazon Dash}

An objective of Amazon Dash is to help users quickly purchase diverse products. Amazon Dash consists of a barcode scanner, and a sensor for voice recognition [16]. On first use, users have to connect the Dash to a Wi-Fi network, and interlock with an Amazon account. If the user scans the barcode of a product, Dash automatically adds the product to the shopping account of the user's Amazon account. Also, the user can call the common noun of a product to Dash, to add the product to the shopping account of the user's Amazon account. However, users have to make a payment to the Annazon account to finish the order.

\subsection{Amazon Dash Button}

Amazon Dash Button enables users to quickly purchase its product just by pushing a button. The Amazon Dash Button consists of a button according to a specific product. Users can dispose of several buttons at any place they want. The button is composed of only one button device. To employ the button, users should first connect the button to a Wi-Fi network through a smartphone application, an assign a product that is connected to the Dash Button via their Amazon account [1t]. When the user presses the button, it is connected with the Amazon account through Wi-Fi, places an order, and makes an automatic payment. The delivery is also processed without any user manipulation.

\subsection{Buddy Cup}

Buddy Cup aims to easily and quickly maintain a virtual friendship through a social network service (SNS), For this, the Buddy Cup enables users to make a friend request on Facebook by tôasting their cups. This product is connected to a mobile application provided by a manufacturer The bottom of the cup has an NFC tag, an NFC sensor, and a QR code [18]. On firs use, the cup needs to be registered with the user's smartphone through scanning of the QR code that is located at the bottom. Through this, the cup is connected to a user's Facebook account via the mobile application. If the cup taps another cup for a toast, the NFC sensor recognizes another NFC tag. A friend request is sent through the mobile application. If the request is completed, the cup shows a red LED light.

\subsection{Nest thermostat}

The purpose of the Nest thermostat is to provide customized temperatures to users through sensing the user's daily patterns and interfacing with weather conditions depending on a user's geographical location. The Nest thermostat is an IoT-based thermostat that provides user-customized services. Users have to manually operate their home temperature in their first week. Based on data collected in the first week, the Nest thermostat provides self-learning functions with machine learning algorithms [19]. For example, through using built-in sensors and smartphone locations, Nest thermostat can grasp the temperatures and times that the user wants. The thermostat automatically controls temperatures at home based on these patterns. Moreover, when the Nest thermostat recognizes that nobody is home, it turns on an energy saving mode, and shows 
a green leaf icon on the thermostat screen [20]. Users can remotely control temperatures via the Nest thermostat with a smartphone, a tablet, or a laptop.

\section{Analysis of Cases}

In this research, we analyzed the cases according to the connected object, mobile application, and platform. Table 1 summarizes the results of our case studies depending on the service goal, service components, stakeholders, and interaction as touchpoints.

\section{Table 1. Case Studies}

\begin{tabular}{|c|c|c|c|c|}
\hline Case & Service goal & $\begin{array}{c}\text { Service } \\
\text { components }\end{array}$ & Stakeholder & Interaction as touchpoints \\
\hline \multirow{4}{*}{ GlowCap } & \multirow{4}{*}{$\begin{array}{l}\text { To care for } \\
\text { patients by } \\
\text { monitoring } \\
\text { medicine taking } \\
\text { schedules }\end{array}$} & \multirow{4}{*}{$\begin{array}{l}\text { - Cap device } \\
\text { - Plug-in } \\
\text { reminder } \\
\text { device } \\
\text { - IoT Platform }\end{array}$} & $\begin{array}{l}\text { User } \\
\text { (patient) }\end{array}$ & $\begin{array}{l}\text { - Receive schedule alarms } \\
\text { - Take medicine } \\
\text { - Receive a text message or phonecal }\end{array}$ \\
\hline & & & Helpers & $\begin{array}{l}\text { - Receive a report of the user taking } \\
\text { their medicine }\end{array}$ \\
\hline & & & Pharmacist & - Confirm a medicine refill request \\
\hline & & & Pro & - Reschedule a user's medicine taking \\
\hline \multirow[t]{2}{*}{$\begin{array}{l}\text { HAPI } \\
\text { Fork }\end{array}$} & \multirow[t]{2}{*}{$\begin{array}{l}\text { To help users } \\
\text { maintain a } \\
\text { healthy eating } \\
\text { habit by using a } \\
\text { real-time alarm }\end{array}$} & \multirow[t]{2}{*}{$\begin{array}{l}\text { - Fork device } \\
\text { - Mobile } \\
\text { application } \\
\text { - Online } \\
\text { dashboard }\end{array}$} & & $\begin{array}{l}\text { of fork serving } \\
\text { - Take recorded information through a } \\
\text { mobile application } \\
\text { - Get statistics through an online } \\
\text { dashboard }\end{array}$ \\
\hline & & & & $\begin{array}{l}\text { - Manage information of an online } \\
\text { dashboard and a mobile application }\end{array}$ \\
\hline \multirow[t]{2}{*}{$\begin{array}{l}\text { Amazon } \\
\text { Dash }\end{array}$} & \multirow[t]{2}{*}{$\begin{array}{l}\text { To quickly } \\
\text { place diverse } \\
\text { products in an } \\
\text { Amazon } \\
\text { account }\end{array}$} & \multirow[t]{2}{*}{$\begin{array}{l}\text { - Amazon } \\
\text { Pash devices } \\
\text { Online } \\
\text { Amazon } \\
\text { account }\end{array}$} & User & $\begin{array}{l}\text { - Connect to a Wi-Fi network } \\
\text { - Add products to a shopping cart by } \\
\text { scanning a product barcode and } \\
\text { using voice recognition } \\
\text { - Make final payment on an Amazon } \\
\text { account }\end{array}$ \\
\hline & & & Provider & - \\
\hline \multirow[t]{2}{*}{$\begin{array}{l}\text { Amazon } \\
\text { Dash } \\
\text { Button }\end{array}$} & \multirow[t]{2}{*}{$\begin{array}{l}\text { To provide a } \\
\text { one-step } \\
\text { purchase }\end{array}$} & \multirow{2}{*}{$\begin{array}{l}\text { Dash Button } \\
\text { device } \\
\text { - Online } \\
\text { Amazon } \\
\text { account } \\
\end{array}$} & User & $\begin{array}{l}\text { - Connect to a Wi-Fi network } \\
\text { - Assign a product } \\
\text { - Deploy a button } \\
\text { - Make an order by pushing the button }\end{array}$ \\
\hline & & & Provider & - Receive a delivery request \\
\hline \multirow[t]{2}{*}{$\begin{array}{l}\text { Buddy } \\
\text { Cup }\end{array}$} & \multirow[t]{2}{*}{$\begin{array}{l}\text { To maintain a } \\
\text { friendship }\end{array}$} & \multirow{2}{*}{$\begin{array}{l}\text { - Cup device } \\
\text { - Mobile } \\
\text { application } \\
\text { - Facebook } \\
\text { account }\end{array}$} & User & $\begin{array}{l}\text { - Connect to a Facebook account } \\
\text { - Tap another user's cup through a } \\
\text { toast } \\
\text { - Check a friend request by a red light }\end{array}$ \\
\hline & & & Provider & - \\
\hline \multirow[t]{2}{*}{$\begin{array}{l}\text { Nest } \\
\text { thermostat }\end{array}$} & \multirow{2}{*}{$\begin{array}{l}\text { To provide } \\
\text { customized } \\
\text { temperatures } \\
\text { though } \\
\text { grasping a } \\
\text { user's patterns }\end{array}$} & \multirow{2}{*}{$\begin{array}{l}\text { - Nest } \\
\text { thermostat } \\
\text { product } \\
\text { - Mobile } \\
\text { application }\end{array}$} & User & $\begin{array}{l}\text { - Manipulate a thermostat } \\
\text { - Wander around the space } \\
\text { - Remotely control a temperature } \\
\text { through a mobile application }\end{array}$ \\
\hline & & & Provider & - \\
\hline
\end{tabular}


Figure 1 illustrates the results of our analyses based on a service cycle of the cases.

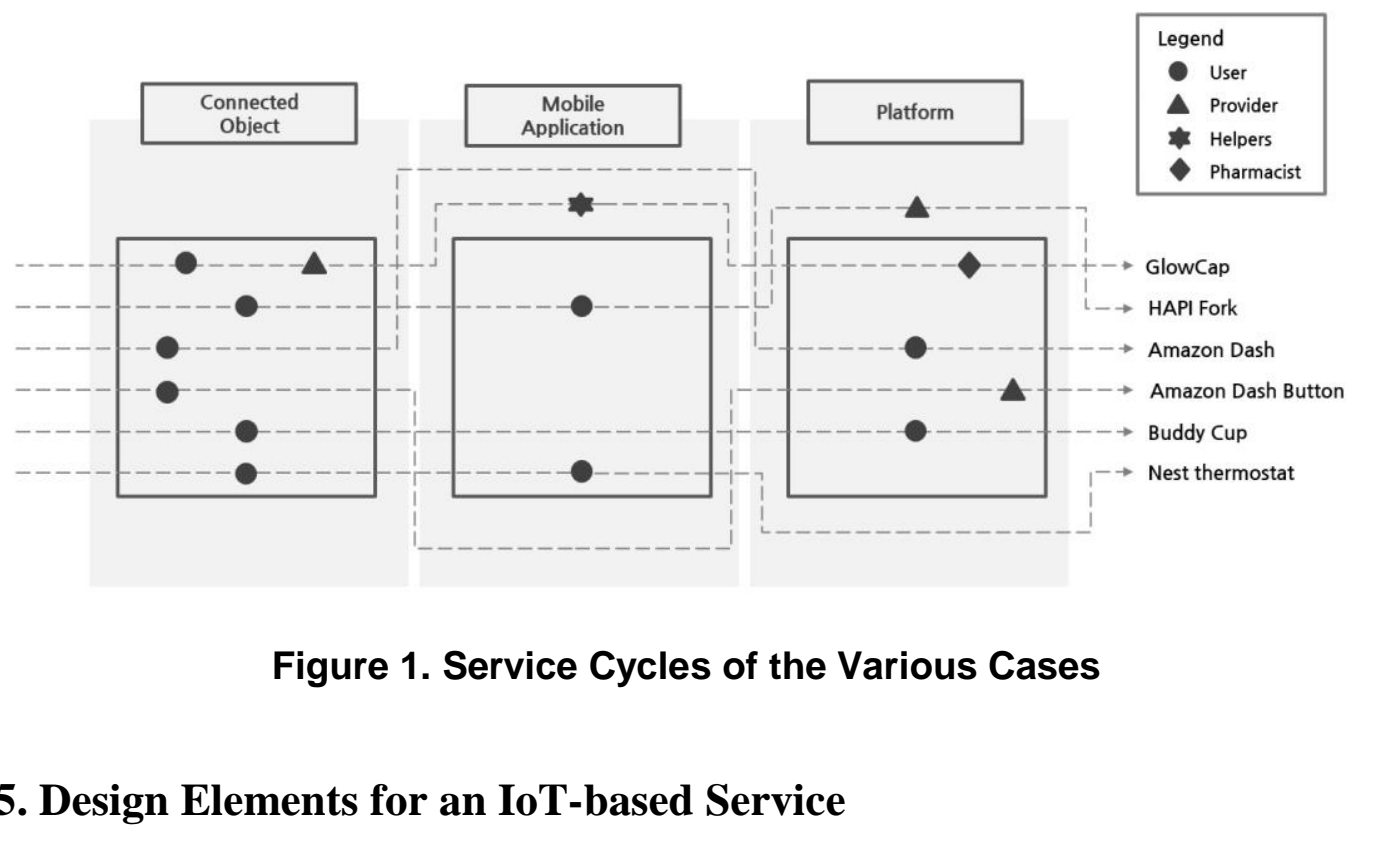

We extracted design elements and built questionnaires for applying the elements, which designers can consider in the process of IoT-based service design from the exploration of literature and cases. Through these questionnaires, designers can apply the design elements to creating their IoT-based service in detail. The design elements can be classified into four: sensing, interactivity, expandability, and personalization. The four design elements that reflect the extracted characteristics of an IoT can be important to an IoT-based service, in order to achieve a service goal through solving problems. Table 2 shows the elements for designing an IoT-based service, and questionnaires depending on how intensively they are applied.

\section{Table 2. Design Erements for an loT-based Service}

\begin{tabular}{|c|c|c|}
\hline $\begin{array}{l}\text { Design El ments as } \\
\text { IoT characteristics }\end{array}$ & $\begin{array}{l}\text { Degree of applying } \\
\text { design elements }\end{array}$ & Questionnaires \\
\hline \multirow{3}{*}{$\begin{array}{l}\text { Sensing: } \\
\text { the scope of } \\
\text { sensing }\end{array}$} & High & Can it sense multiple objects? \\
\hline & Medium & Can it sense one object? \\
\hline & Low & Can it employ a sensor? \\
\hline \multirow{3}{*}{$\begin{array}{l}\text { Interact vity: } \\
\text { the degree of } \\
\text { interaction }\end{array}$} & High & Can it support a multi-loop system? \\
\hline & Medium & Can it support a single-loop system? \\
\hline & Low & Can it support a responsive system? \\
\hline \multirow{3}{*}{$\begin{array}{l}\text { Expandability: } \\
\text { the degree of } \\
\text { data connection }\end{array}$} & High & $\begin{array}{l}\text { Can it involve multiple stakeholders or } \\
\text { users in an IoT-based service? }\end{array}$ \\
\hline & Medium & $\begin{array}{l}\text { Can users check information generated } \\
\text { in an IoT-based service? }\end{array}$ \\
\hline & Low & Can users directly control objects? \\
\hline \multirow{3}{*}{$\begin{array}{l}\text { Personalization: } \\
\text { the degree of user } \\
\text { customization }\end{array}$} & High & $\begin{array}{l}\text { Can it provide customized service to } \\
\text { users? }\end{array}$ \\
\hline & Medium & $\begin{array}{l}\text { Can it provide different services to } \\
\text { users? }\end{array}$ \\
\hline & Low & Can it pro \\
\hline
\end{tabular}




\section{Application of Cases}

The main purpose of this chapter is to prove the validity of the extracted design elements. For this, we analyzed how the characteristics of an IoT are reflected through applying the design elements to IoT-based services. Through this, we can understand how the design elements help achieve the service goal in each IoT-based service. Table 3 shows the results of the analysis according to the degree of applying design elements.

\section{Table 3. Application of Cases}

\begin{tabular}{|c|c|c|c|c|}
\hline Cases & Sensing & Interactivity & Expandability & Personalization \\
\hline GlowCap & D & O & 0 & \\
\hline HAPI Fork & O & O & $\mathbf{0}$ & \\
\hline Amazon Dash & ○ & $\bigcirc$ & & \\
\hline Amazon Dash Button & $\bigcirc$ & $\bigcirc$ & & ح \\
\hline Buddy Cup & D & O & & $\bigcirc$ \\
\hline Nest thermostat & O & & & (D \\
\hline
\end{tabular}

GlowCap has high expandability through supporting an IoT platform environment in which multiple stakeholders can communicate with each other. Moreover, although Buddy cup doesn't have its own platform, the-Buddy cup enables users to expand friends through connecting to an SNS. Through this expandability, the service goals of GlowCap and the Buddy cup can be achieved However, HAPI Fork could not achieve its goal merely by providing the formation of the user's eating habits. Because of this, a HAPI Fork provider started to develop a platform in which diverse users could participate to improve communication among users. This enables this service to achieve its goal.

The goal of Amazon Dash is to get users to quickly add diverse products to their shopping cart. To achieve this goal, the capability to sense different products became important to Amazon Dash. Thus, the Amazon Dash device helps users easily place diverse products by scanning and voice recognition technology. However, Amazon Dash Button doesn't need to sense different products to accomplish its goal, since it aims to provide a one-step service that can simplify complicated purchase processes by pushing a button. Thus, the Amazon Dash Button strengthens the personalization of a product, while it lower the application of other design elements. This can be considered as providing highly personalized products to users. The Nest Thermostat provides a suitable emperature through analyzing the user's movements. This thermostat functions as a learning system that supports multi-loop feedback control. This multi-loop feedback control can be considered as high interactivity of a design element.

As these cases show, each IoT-based service achieves its service goal through applying design elements that come from characteristics of the IoT. Therefore, these design elements need to be employed as a method to design and analyze recent interactive products that are connected to a network. 


\section{Method to Design and Analyze an IoT-based Interactive Product}

In this research, we propose a method to design and analyze an IoT-based interactive product. This method proposes the design elements that designers need to consider in a design process of an interactive product in order to achieve the goal of the IoT-based service. For this, we categorized the design elements into four controllable factors: input, control, output, and connectivity. These factors come from three essential factors together with connectivity, which is the most important IoT characteristic. Designers can think of what elements to apply according to this process. Thus, this method will allow interactive products to achieve their goal in an IoT-based service. Figure 2 shows the method to design and analyze an interactive product as a connected object, based on the design elements for creating an IoT service. With this method, designers and developers can effectively create an interactive product.

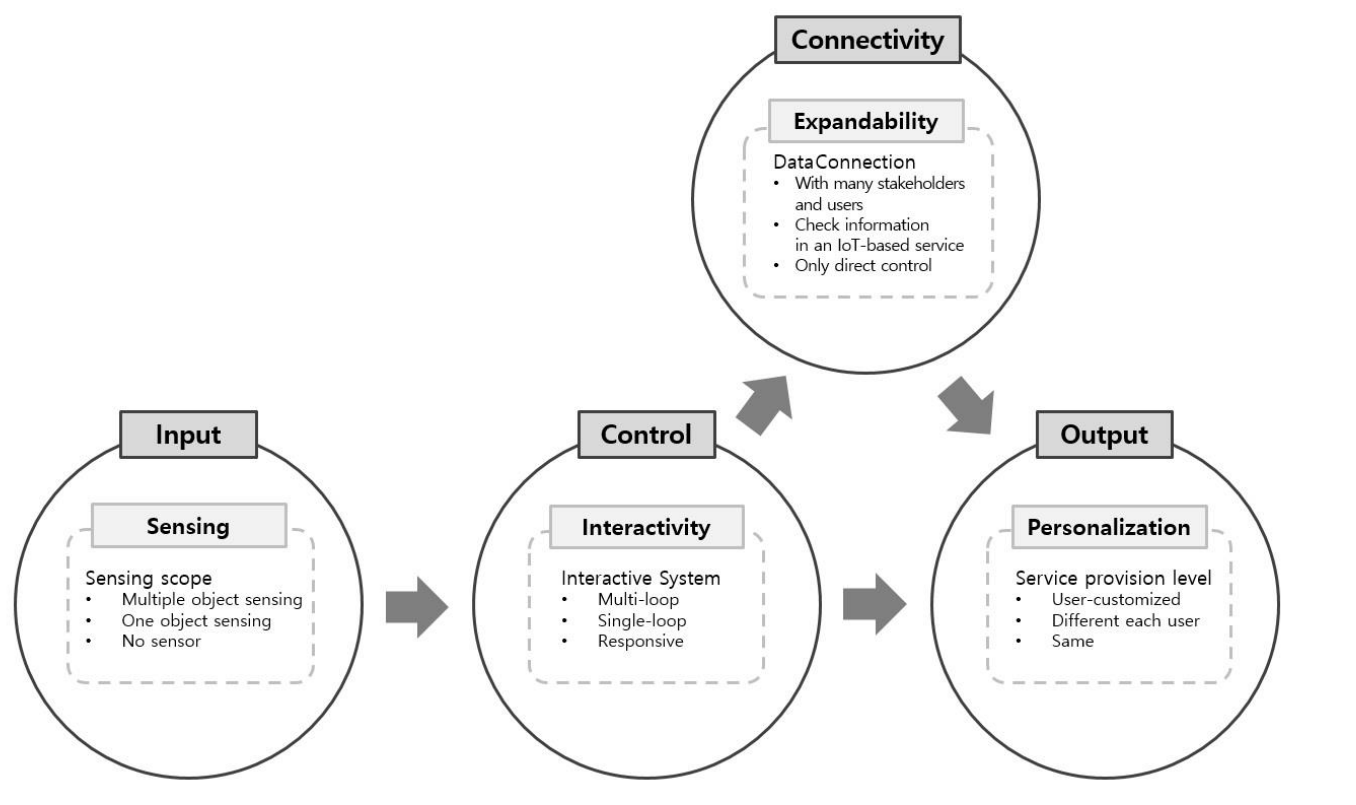

Figure 2 Method to Design and Analyze an Interactive Product

\section{Conclusion and Further Works}

The research aims to provide a method to design and analyze an interactive product as an IoT-based seryice to designers. The method proposed in this research was built based on the extracted four design elements of sensing, interactivity, expandability, and personalization. Moreover, in order to prove the validity of the extracted design elements, design elements were applied to different cases, and analyzed.

In this paper, the key findings were: (1) the design elements proposed in this research can be employed as the main goal of the interactive product connected to an IoT platform andor a mobile application, and (2) IoT-based interactive products need to be considered with four controllable factors, rather than the existing three factors, i.e. input, control, output, and connectivity.

Therefore, this study is expected to contribute to helping designers and students expand the scope of interactive product design. The further work of this research includes expanding the design elements, and then developing a toolkit for interactive design based on the design method proposed in this research. 


\section{References}

[1] N. Gershenfeld, "When things start to think", Owl Books, New York, (2000).

[2] T. Baines, H. Lightfoot, J. Peppard, M. Johnson, A. Tiwari, E. Shehab and M. Swink, "Towards an operations strategy for product-centric servitization", International Journal of Operations \& Production Management, vol. 29, no.5, (2009), pp. 494-519.

[3] https://en.wikipedia.org/wiki/Service design.

[4] D. Evans, "The Internet of Things: How the next evolution of the internet is changing everything", Cisco White paper, San Jose, (2011).

[5] ITU-T, "Overview of the Internet of things ", International Telecommunication Union, Geneva, (2013).

[6] H. Shin, B. Jeon and J. W. Park, "Elements for New Service Blueprinting Supporting IoT-based Service Design", Proceedings of the 5th International Workshop on Art, Culture, Game, Graphics, Broadcasting and Digital Contents 2016, Jeju Island, Korea, August 16-19, (2016).

[7] L. G. Zomerdijk, and C. A. Voss, "Service design for experience-centric services", Journal of Service Research, vol.13, no.1, (2010), pp. 67-82.

[8] M. E. Porter and J. E. Heppelmann, "How Smart, Connected Products Are Transforming Competition", Harvard Business Review, vol.92, no.11, (2014), pp.64-88.

[9] C. Crawford, "The Art of Interactive Design: a euphonious and illuminating guide to buildingsuccessiul software", No Starch Press, San Francisco, (2002).

[10] J. A. Stankovic, "Research directions for the internet of things", IEEE Internet of Things Journal, vol.1, no.1, (2014), pp. 3-9.

[11] W. Lee and J.W. Park, "Development of a Co-Creation Environment for an Open IoT Platform", International Journal of Multimedia and Ubiquitous Engineering, vol. 10, no.10, (2015), pp. 291-302.

[12] J. Mineraud, O. Mazhelis, X. Su and S. Tarkoma, "A gap analysis of Internet-of-Things platforms", Computer Communications, vol.89-90, (2016), pp. 5-16

[13] N. M. Goldfarb, "Improving subject compliance with smart pill bottles Journal of Clinical Research Best Practices, vol.3, no.8, (2007), pp. 1-5.

[14] M. L. Lee and A. K. Dey, "Real-time feedback for improving medication taking", In Proceedings of the 32nd annual ACM conference on Human factors in computing systems, Toronto, Canada, (2014), April 26 - May 1.

[15] O. Zuckerman, T. Gal, T. Keren-Capelovitch, T. Karsorsky, A. Gal-Oz, and P. L. T. Weiss, "DataSpoon: Overcoming Design Challenges in Tangble and Embedded Assistive Technologies", In Proceedings of the TEI'16: Tenth International Conference on Tangible, Embedded, and Embodied Interaction, Eindhoven, Netherlands, (2016), Febuary 2- 17.

[16] A. M. French and J. P. Shim, "The Digital Revolution: Internet of Things, 5G, and Beyond" Communications of the Association for Information Systems, vol.38, no.1, (2016), pp. 840-850.

[17] M. V. Maier, "The Internet of Things (Iô): what is the potential of Internet of Things applications for consumer marketing?" Bachelor Thesis, University of Twente, Enschede, (2016).

[18] L. Wan, C. Zhang and D. Min, "Ântecendents to privacy concern over ubiquitous service in china", Journal of Inte mational \& Commerce, vol.9, no.2, (2013), pp. 171-194.

[19] G. Hernandez, O. Arias, D. Buentello and Y. Jin, "Smart nest thermostat: A smart spy in your home", Black Hat US A, (2014)

[20] R. Yang and M. W. Newman, "Living with an intelligent thermostat: advanced control for heating and cooling systems", In Proceedings of the 2012 ACM Conference on Ubiquitous Computing, Pittsburgh, USA, (2012), Septeniber 5-8.

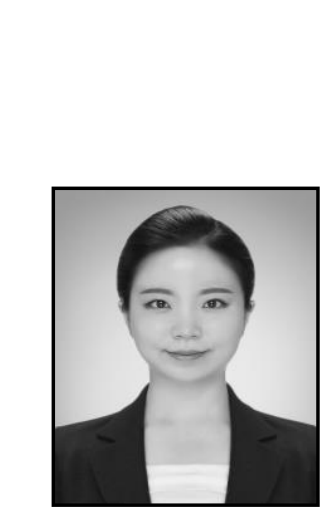

\section{Authors}

Hyeji Shin, She is an undergraduate student at the Global School of Media, Soongsil University. She is interested in designing and analyzing IoT based services which are taking a service design approach. 


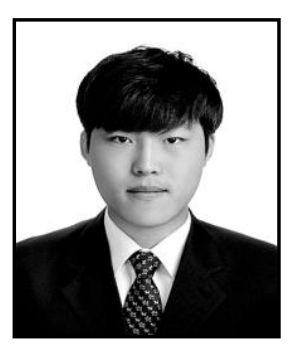

Bienil Jeon, He is a Master's candidate at the department of Digital Media, Soongsil University, and a member of the Hybrid Media Lab. He holds a bachelor's degree from the Global School of Media, Soongsil University. $\mathrm{He}$ is interested in developing innovative smart, connected products based on IoT platforms that bridge the gap between the physical and the virtual.

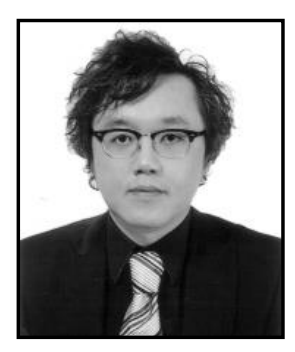

Jae Wan Park, He is an assistant professor at the department of Digital Media, Soongsil University, and the director of the Hybrid Media Lab. He holds a doctoral degree and a master's degree from Harvard University's Graduate School of Design. He also received a bachelor's degree from Ajou University. Before joining Soongsil University, he had three and a half years of industriar experience working at Cheil Worldwide as a director, KT (Korea Telecom) as a researcher, and Junglim architecture as an architectural designer. Recently, he received the Best Project Award for Cooperative R\&D between Industry, Academy, and Research Institute from the Small and Medium Business Administration. Additionally, he was the winner of the Harvard University 2008 Digital Design Prize for the most creative use of digital media, and has been awarded the 2008 Young CAADRIA Award, which acknowledges his contribution in research to the field of desig and computation. His research explores the fusion of the physical and the virtual. His recent research focus includes the integration of physical computing into products, space, architecture and cities based on design thinking for innovation.

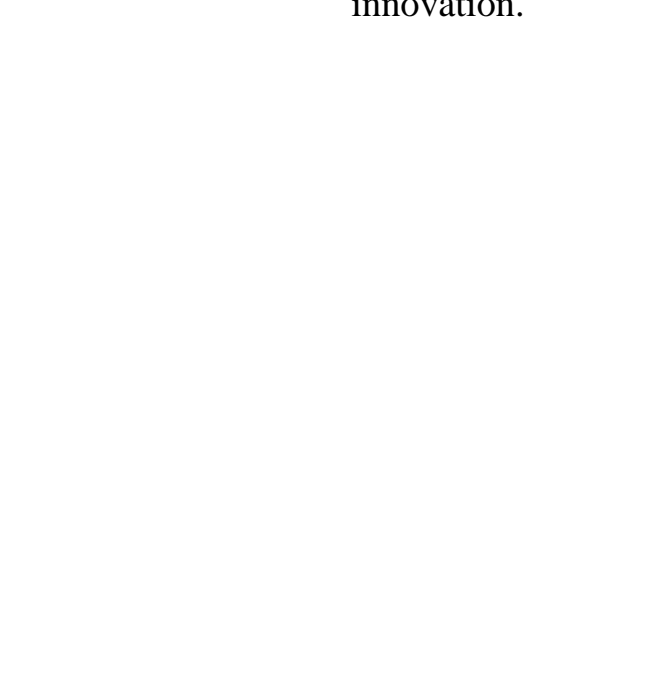

